\title{
Synthesis of theaflavins with Camellia sinensis cell culture and inhibition of increase in blood sugar values in high-fat diet mice subjected to sucrose or glucose loading
}

\author{
Masumi Takemoto*,a ${ }^{*}$, Hiroaki Takemoto ${ }^{\mathrm{b}}$, Asuka Sakurada ${ }^{\mathrm{c}}$ \\ ${ }^{a}$ School of Pharmaceutical Sciences, Ohu University, 31-1 Tomitamachi-Aza Misumido, Koriyama, 963-8611, \\ Japan; ${ }^{b}$ School of Pharmaceutical Sciences, Kitasato University, 5-9-1 Shirokane, Minato-ku, Tokyo, 108-8641, \\ Japan; ${ }^{c}$ School of Pharmaceutical Sciences, University of Shizuoka, 52-1 Yada, Shizuoka 422-8526, Japan
}

\begin{abstract}
Theaflavin and its galloyl esters are major polyphenolic pigments of black tea. We compared the efficiency of a variety of oxidizing enzyme systems to synthesize theaflavin and its galloyl esters. Camellia sinensis cell culture efficiently synthesized theaflavin from epicatechin and epigallocatechin with $70 \%$ yield and $100 \%$ conversion in $4 \mathrm{~min}$. In an administration experiment performed in mice, theaflavin inhibited the increase blood glucose levels in mice that were fed a high-fat diet and subjected to glucose or sucrose loading in mice.
\end{abstract}

Key words: theaflavin, theaflavin galloyl esters, Camellia sinensis cell cultures, attenuation of blood sugar level increase

Theaflavin (TF) and its galloyl esters are the main red pigments in black tea, and have recently been shown to exhibit various anti-obesity ${ }^{1)}$, glucose-lowering ${ }^{2)}$ and anticancer ${ }^{3)}$ effects. Therefore, it has become recognized as potentially useful not only as a natural coloring agent but also as a bioactive substance. However, further research on the compound is required. TF has no galloyl esters. Theaflavin's galloyl esters have three different galloyl esters: theaflavin-3-O-gallate (TF3G), theaflavin-3'-O-gallate (TF3'G), and theaflavin-3,3'di- $O$-gallate (TFDG). Their chemical structures are shown below in Scheme 1.

Scheme 1. The chemical structures of TF, TF3G, TF3'G, and TFDG
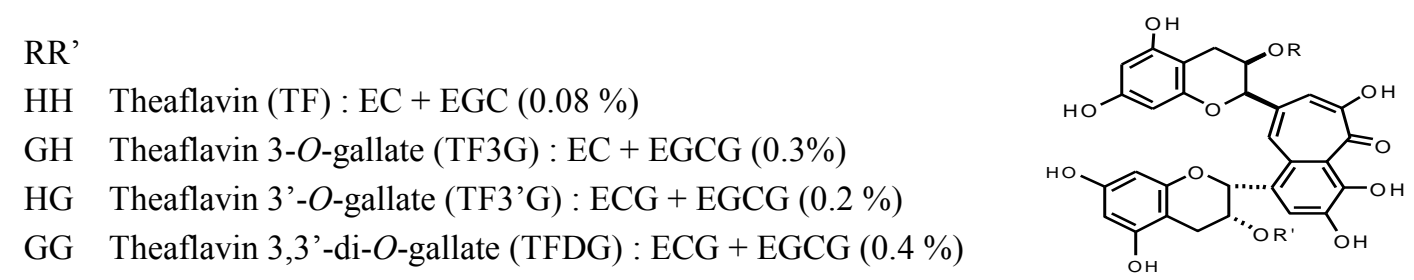

TF and its galloyl esters (TF3G, TF3'G, TFDG) are produced from their parent catechins [epicatechin (EC), epigallocatechin (EGC), epicatechin gallate (ECG), and epigallocatechin3-O-gallate (EGCG)] by polyphenol oxidase or peroxidase in tea leaves during production of black tea leaves or in tea fermentation, and are obtained by extraction from black tea ${ }^{4), 5}$. However, the content in black tea is extremely low as shown in Scheme $1^{6)}$. Therefore, it has 
been difficult to obtain a sufficiently usable amounts of TF and its galloyl esters simply by extraction from black tea leaves.

$\mathrm{TF}$ is biosynthesized from EC and EGC. TF3G is biosynthesized from EC and EGCG. TF3' $G$ is biosynthesized from ECG and EGC and TFDG is biosynthesized from ECG and EGCG (Scheme 1) ${ }^{4), 5}$. Development of the use of enzymes for oxidative reactions, which is a green chemistry approach, has been increasing in recent years. Horseradish peroxidase (HRP) is a commercially available metalloporphyrin enzyme. We observed that Camellia $(C$.) sinensis cell culture is a rich source of peroxidase (POD) enzymes ${ }^{7)}$. Therefore, we applied them to the oxidative coupling of 2-naphthol derivatives ${ }^{8)}$ and production of a variety of biologically active compounds ${ }^{7}$. In this study, we report a method using $C$. sinensis cell culture for efficient synthesis of TF from EC and EGC with high yield ${ }^{9}$.

To investigate the synthesis of TF by oxidation of EC and EGC, we surveyed a variety of oxidizing agents [commercial polyphenol oxidase (PPO) (Funakoshi Co., Ltd), commercial $\mathrm{HRP}^{10)}$ (Wako Co., Ltd), C. sinensis cell culture, Nicotiana(N.) tabacum cell culture ${ }^{7)}$, and Daucus (D.) carota cell culture ${ }^{7)}$ to optimize conditions as shown in Table 1 . Synthesis of TF from EC (20mg) and EGC (21 mg) was performed with stirrer. A) 10mg PPO was added to a mixture of EC and EGC in $0.1 \mathrm{M} \mathrm{H}_{3} \mathrm{PO}_{4}$ buffer ( $\left.\left.\mathrm{pH} 6,20 \mathrm{ml}\right), \mathrm{B}\right) 10 \mathrm{mg} \mathrm{HRP}$ was added to a mixture of EC and EGC in $0.1 \mathrm{M} \mathrm{H}_{3} \mathrm{PO}_{4}$ buffer $(\mathrm{pH} 6,20 \mathrm{ml})$, acetone $(2 \mathrm{ml})$, and $3 \% \mathrm{H}_{2} \mathrm{O}_{2}$ $(0.5 \mathrm{ml}), \mathrm{C}) 10 \mathrm{ml}$ of plant cell culture was added to a mixture of EC and EGC in $0.1 \mathrm{M}$ $\mathrm{H}_{3} \mathrm{PO}_{4}$ buffer $(\mathrm{pH} 6,20 \mathrm{ml})$, acetone $(2 \mathrm{ml})$, and $3 \% \mathrm{H}_{2} \mathrm{O}_{2}(0.5 \mathrm{ml})$.

As shown in Table 1 as oxidizing agent entry 3, EC and EGC were converted into TF in 15 min with $48 \%$ yield as the sole product, and the residual starting materials (EC, EGC) were absent. For the other oxidizing agents (entries 1, 2, 4, and 5), yields of TF were low, and the starting materials (EC, EGC) were recovered. For $C$. sinensis cell culture (entry 6), a shortened reaction time led to the highest chemical yield of TF. We succeeded in quantitative synthesis of TF as the sole product with $70 \%$ yield and $100 \%$ conversion from EC and EGC in $C$. sinensis cell culture with a reaction time of $4 \mathrm{~min}$. Fig 1 shows HPLC chromatogram of

Table 1. Synthesis of $\mathrm{TF}^{11)}$ with oxidizing agents

\begin{tabular}{|l|l|c|c|c|c|l|l|c|c|}
\hline No & $\begin{array}{l}\text { Oxidizing } \\
\text { agents }\end{array}$ & $\begin{array}{c}\text { Time } \\
(\mathrm{min})\end{array}$ & $\begin{array}{c}\text { Y. } \\
(\%)\end{array}$ & $\begin{array}{c}\text { Recovered } \\
\text { EC }(\%)\end{array}$ & No & $\begin{array}{l}\text { Oxidizing } \\
\text { agents }\end{array}$ & $\begin{array}{c}\text { Time } \\
(\mathrm{min})\end{array}$ & $\begin{array}{c}\text { Y. } \\
(\%)\end{array}$ & $\begin{array}{c}\text { Recovered } \\
\text { EC }(\%)\end{array}$ \\
\hline 1 & PPO & 18 & 29 & 49 & 4 & N. tabacum & 15 & 25 & 45 \\
\hline 2 & HRP & 60 & 30 & 28 & 5 & D. carota & 15 & 19 & 51 \\
\hline 3 & C. sinensis & 15 & 48 & 0 & 6 & C. sinensis & 4 & 70 & 0 \\
\hline
\end{tabular}

TF synthesis (entry 6 at reaction time $1 \mathrm{~min}$ ). Peak at $3.6 \mathrm{~min}$ is EGC and peak at $4.4 \mathrm{~min}$ is EC. Fig 2 shows HPLC chromatogram of TF synthesis (entry 6 at reaction time 4 min). Peak at $14.2 \mathrm{~min}$ is TF. These HPLC chromatogram shows that all EC and EGC were converted to TF. Fig 3 illustrates the time course of entry 3. TF increased with reaction times, reaching maximum and decreased. On the other hand, EC and EGC decreased in 4 min, reaching $0 \%$. For a typical experiment, TF was separated from the reaction mixture and purified after the synthetic reaction was completed. TF-containing extraction residues may be separated and 


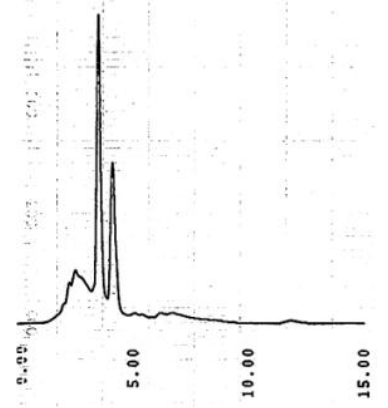

Fig1

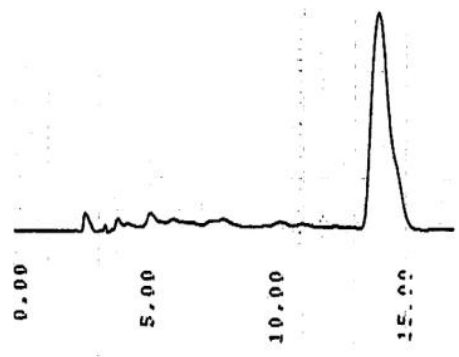

Fig2

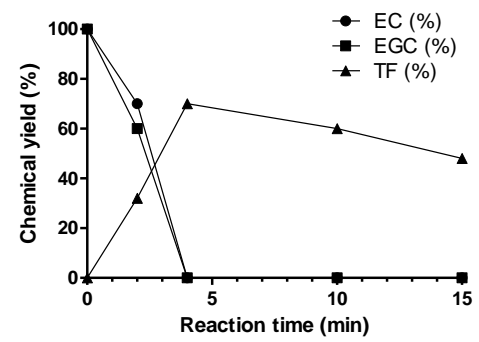

Fig 3

purified using techniques such as column chromatography. However, column chromatography of TF mixtures containing EC and EGC led to the decomposition of TF which lowered its yield. Because the method shown in entry 6 produced TF alone, it was possible to obtain the target substance with high purity by solvent extraction of the reaction mixture. In a typical experiment, EC (290 mg) and EGC (306 mg) were added to a mixture of acetone and phosphate buffer $(\mathrm{pH} 6.0)(1: 10 \mathrm{v} / \mathrm{v}, 100 \mathrm{ml}), C$. sinensis cell culture $(50 \mathrm{ml}$ including $10.2 \mathrm{~g}$ cells), and $3 \% \mathrm{H}_{2} \mathrm{O}_{2}(0.8 \mathrm{ml})$. The mixture was stirred for 4 min and then extracted using $\mathrm{CH}_{3} \mathrm{COOEt}$. Further, the organic layer was dried over anhydrous $\mathrm{MgSO}_{4}$ and concentrated in vacuo to provide TF ( $395 \mathrm{mg}$ ) with $70 \%$ yield and $100 \%$ conversion. In the HPLC analysis ${ }^{12}$, peaks for EC, and ECG were virtually absent, but a peak for TF was observed.

According to the established procedure described above, we used HRP, PPO, or C. sinensis cell culture to synthesize TF3G from EC and EGCG, TF3'G from ECG and EGC, and TFDG from ECG and EGCG. These results are summarized in Table 2. With respect to the yields of all TF3G, TF3'G, and TFDG, C. sinensis cell culture was not superior to PPO or HRP. These results (Tables 1 and 2) suggest that $C$. sinensis cell culture contains a specific enzyme for synthesis of TF from EC and EGC.

Table 2. Synthesis using different oxidizing agents to produce TF $3 \mathrm{G}$, TF3' G, and TFDG ${ }^{11)}$

\begin{tabular}{|l|l|c|c|l|l|l|l|l|c|}
\hline No & TFs & $\begin{array}{l}\text { Oxidizing } \\
\text { agents }\end{array}$ & $\begin{array}{l}\text { Time } \\
(\mathrm{min})\end{array}$ & $\begin{array}{l}\text { Y. } \\
(\%)\end{array}$ & No & TFs & $\begin{array}{l}\text { Oxidizing } \\
\text { agents }\end{array}$ & $\begin{array}{l}\text { Time } \\
(\mathrm{min})\end{array}$ & $\begin{array}{l}\text { Y. } \\
(\%)\end{array}$ \\
\hline 1 & TF3G & HRP & 90 & 10 & 6 & TF3'G & C. sinensis & 120 & 6 \\
\hline 2 & TF3G & PPO & 50 & 19 & 7 & TFDG & HRP & 120 & 5 \\
\hline 3 & TF3G & C. sinensis & 12 & 15 & 8 & TFDG & PPO & 120 & 10 \\
\hline 4 & TF3'G & HRP & 120 & 14 & 9 & TFDG & C. sinensis & 120 & 5 \\
\hline 5 & TF3'G & PPO & 90 & 10 & & & & & \\
\hline
\end{tabular}

The effect of TF on inhibition of increases in blood sugar values in mice was evaluated ${ }^{13)}$. Oral administration of TF $(30.6 \mathrm{mg} / \mathrm{kg})$ to 5 -week-old C57BL6 mice $(\mathrm{n}=6)$ significantly inhibited increases in blood glucose in a sucrose loading test $(2 \mathrm{~g} / \mathrm{kg})$ relative to the effect of administration of distilled water in control mice (maximum blood sucrose levels 20 min after administration of TF: $195.0 \pm 22.4 *$, control: $220.0 \pm 8.2$ ). Five-week-old C57BL6 mice were provided with TF ad libitum $(5 \mathrm{mg} / 15 \mathrm{ml}$ water) and a high-fat diet, Quick Fat. When the 
mice $(\mathrm{n}=7)$ were 16 -weeks-old, sucrose $(2 \mathrm{~g} / \mathrm{kg})$ or glucose $(2 \mathrm{~g} / \mathrm{kg})$ was administered. Increases in blood glucose levels were significantly inhibited relative to those in the control group of mice that received distilled water (blood sucrose levels $40 \mathrm{~min}$ after sucrose administration of TF: $234.0 \pm 19.8^{* *}$, control:309.3 \pm 27.0 ; blood glucose levels 20 min after glucose administration of TF: 407.6 $\pm 35.6^{*}$, control:482.6 \pm 17.2 ). The fasting blood sugar level was used as a baseline to calculate the area under the blood sugar elevation curve ( $\triangle \mathrm{AUC}$ ). The sugar data $\triangle \mathrm{AUC}$ was tabulated relative to the water $\triangle \mathrm{AUC}$ set as 100 to obtain

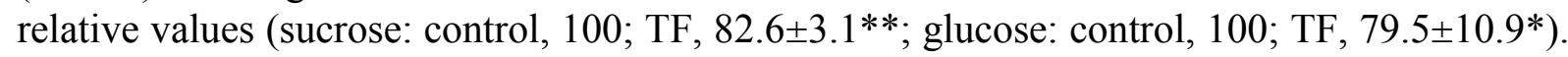
The $\triangle \mathrm{AUC}$ of TF was significantly suppressed relative to that of the $\triangle \mathrm{AUC}$ of the control. These results indicated that TF significantly inhibited increases in blood sugar levels when glucose or sucrose was orally administered to mice. The mechanism underlying inhibition of elevated blood sugar levels was not investigated in this experiment. Further studies are in progress.

\section{Acknowledgements}

This work was supported in part by a project of the Shizuoka Prefecture and Shizuoka City Collaboration of Regional Entities for the Advancement of Technological Excellence, Japan Science and Technology Agency (JST).

\section{References and Notes}

1. Du, Y. T., Wang, X., and Tian, W. X.; J. Enzyme Inhib. Med. Chem., 2005, 20, 349-356.

2. Matsui, T., Tanaka, T., Tamura, S., Toshia, A., Tamaya, K., Miyata, Y., Tanaka, K., and Matsumoto, K., J. Agric. Food Chem., 2007, 55,99-105.

3. Hennings, S. M., Aronson, W., Niu, Y., Conde, F., Lee, N. H., Seeram, N. P., Lee, R. P., Lu, J., Harris, D. M., Moro, A., Hong, J., Shan, L. P., Barnar, R. J., Ziaee, H. G, Gasthy, G., Go, V. W., Wang, H., and Heber, D., J. Nutr., 2006, 1839-1843.

4. Tanaka, T., Mine, C., Inoue, K., Matsuda M., and Kouno, I., J. Agric. Food chem., 2002, 50, 2142-2148.

5. Sang, S., Yang, C. S., and Ho, C-T., Phytochemistry reviews, 2004, 3, 229-241.

6. Coxon, D. T., Holms, A., and Ollis W. D.,Tetrahedron Lett., 1970, 5241-5247.

7. Takemoto, M., Aoshima, Y., Stoynov, N., and Kutney, J. P., Tetrahedron Lett., 2002, 43, 6915-6917.

8. Takemoto, M., Suzuki, Y., and Tanaka, K., Tetrahedron Lett., 2002, 43,8499-8501.

9. Takemoto, M., Japanese Patent No 4696302.

10. Sang, S., Lambert, J. D., Tian, S., Hong, J., Hou, Z., Ryu J-H., Stark, R. E., Rosen, R. T., huang M-T., Yang C. S., and Ho, C-T., Bioorganic \& Medicinal Chemistry, 2004, 12, 459-467.

11. The structures of TF, TF3G, TF3' G, and TFDG were confirmed by a comparison of the ${ }^{1} \mathrm{H}-\mathrm{NMR}$, FAB-MS data, and HPLC with authentic samples.

12. A JASCO HPLC system (PU-980, UV-970) and a $4.6 \mathrm{~mm} \times 250 \mathrm{~mm}$ ODS120A column (TOSO) were used with the following HPLC analytical conditions: solvent: acetonitrile : $\mathrm{CH}_{3} \mathrm{COOEt}$ : 0.05\% $\mathrm{H}_{3} \mathrm{PO}_{4}$ (21:3:76); flow rate, 1.0 $\mathrm{ml} / \mathrm{min}$; temperature, $25^{\circ} \mathrm{C}$; with $\mathrm{UV}$ detection at UV $280 \mathrm{~nm}$. 
13. All data are expressed as means \pm SEs. The statistical significance of differences between groups were analyzed as follows: Student's $t$-test was used after the $F$-test to analyze differences between groups in the experiments involving two experimental groups. $P$-values less than 0.05 were considered to indicate statistical significance. 